\title{
CLEMENS ALEXANDRINUS BAND I
}

\section{Finleitung}

Seite

A. Zeugnisse . . . . . . . . . . . . . . . . . . . . . IX IX

B. Handschriften.

1. Protrepticus und Paedagogus.

a. Parisinus graecus 451 . . . . . . . . . . . . . . . XVI

b. Verzeichnis der von $\mathrm{P}$ abhångigen Handschriften . . . . XXIV

c. Mutinensis III. D. 7 . . . . . . . . . . . . . . . . XXV XXV

d. Laurentianus V 24 . . . . . . . . . . . . . . . . XXVII

e. Orthographie der Handschriften . . . . . . . . . . . XXXII

2. Stromata, Excerpta ex Theodoto, Eclogae propheticae . . . . XXXIX

3. Quis dives salvetur . . . . . . . . . . . . . . . . . X XLII

4. Adumbrationes . . . . . . . . . . . . . . . . . . X XLV

C. Indirecte Überlieferung.

1. Excerpthandschriften . . . . . . . . . . . . . . . . XLVII

2. Catenen
a. Allgemeines . . . . . . . . . . . . . . . . . . . . LII

b. Verzeichnis der Catenen zu den einzelnen Büchern . . . . LIV

3. Florilegien.

a. Die Sacra Parallela des Johannes von Damaskus. . . . . LVIII

b. Die übrigen Florilegien . . . . . . . . . . . . . . LX

4. Citate bei Späteren. . . . . . . . . . . . . . . . . LXIV

D. Ausgaben.

1. Sämtliche Werke . . . . . . . . . . . . . . . . . LXV

2. Einzelne Schriften.
a. Stromata VII. Buch.
b. Quis dives salvetur
LXXIV
c. Excerpta ex Theodoto und Eclogae propheticae . . . . . .
d. Adumbrationes . . . . . . . . . . . . . . . . . . . .)
e. Hymnus auf Christus . . . . . . . . . . . . . . . . . . . . . . . .
LXXV
f. Fragmente . . . . . . . . . . . . . . . . . . LXXVII 
E. Übersetzungen.

1. Die lateinische Ubersetzung . . . . . . . . . . . . . . LXXVII

2. Obersetzungen in moderne Sprachen . . . . . . . . . . LXXIX

F. Bemerkungen zu der vorliegenden Ausgabe . . . . . . . . . LXXX

Nachtrăge und Berichtigungen . . . . . . . . . . . . . . . LXXXV

Text

Protrepticus. . . . . . . . . . . . . . . . . . . . . . . 1

Paedagogus I-III . . . . . . . . . . . . . . . . . . . . . . . . 8

Scholien

Zum Protrepticus . . . . . . . . . . . . . . . . . . 295

Zum Paedagogus . . . . . . . . . . . . . . . . . . . 319

Register zu den Scholien

I. Stellenregister

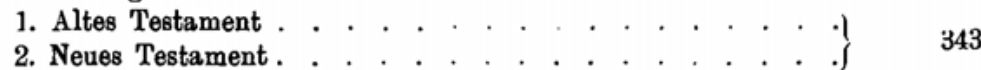

3. Nichtbiblische Schriften . . . . . . . . . . . . . . . 344

II. Namenregister . . . . . . . . . . . . . . . . . . 345

III. Wort- und Sachregister . . . . . . . . . . . . . . . . . $\quad 349$ 